\title{
Article
}

\section{Cyclic Behavior of Calcareous Sand from the South China Sea}

\author{
Lu Liu ${ }^{1,2}$, Xiaofei Yao ${ }^{1,2}$, Zhanpeng Ji ${ }^{1,2}$, Hongmei Gao ${ }^{1,2, *}$, Zhihua Wang ${ }^{1,2}$ and Zhifu Shen ${ }^{1,2}$ \\ 1 Urban Underground Space Research Center, Nanjing Tech University, Nanjing 210009, China; \\ 1liu@njtech.edu.cn (L.L.); 202061225080@njtech.edu.cn (X.Y.); 201821024252@njtech.edu.cn (Z.J.); \\ wzh@njtech.edu.cn (Z.W.); zhifu.shen@njtech.edu.cn (Z.S.) \\ 2 Institute of Geotechnical Engineering, Nanjing Tech University, Nanjing 210009, China \\ * Correspondence: hongmei54@njtech.edu.cn
}

check for

updates

Citation: Liu, L.; Yao, X.; Ji, Z.; Gao, H.; Wang, Z.; Shen, Z. Cyclic Behavior of Calcareous Sand from the South China Sea. J. Mar. Sci. Eng. 2021, 9, 1014. https://doi.org/10.3390/ jmse9091014

Academic Editor: Rodger Tomlinson

Received: 6 August 2021

Accepted: 13 September 2021

Published: 16 September 2021

Publisher's Note: MDPI stays neutral with regard to jurisdictional claims in published maps and institutional affiliations.

Copyright: (c) 2021 by the authors. Licensee MDPI, Basel, Switzerland. This article is an open access article distributed under the terms and conditions of the Creative Commons Attribution (CC BY) license (https:/ / creativecommons.org/licenses/by/ $4.0 /)$.

\begin{abstract}
This study examines the cyclic behavior of calcareous sand obtained from the South China Sea. A series of undrained cyclic triaxial tests were performed on the calcareous sand with various relative densities, cyclic stress ratios, and effective confining pressures. The test results show that whereas the effective confining pressure exhibited a small influence on the cyclic behavior of the calcareous sand, the effect of changes in CSR and relative density was notable. Due to its angular nature, the liquefaction resistance of calcareous sand was much higher than that of silica sand. In addition, differences between calcareous and silica sands in terms of pore pressure generation characteristics and deformation responses were also observed.
\end{abstract}

Keywords: calcareous sand; cyclic triaxial test; liquefaction; cyclic strength

\section{Introduction}

Calcareous sand is a typical marine sediment that is widely distributed in tropical and subtropical areas. In these areas, the replacement of silica sand with calcareous sand as filling material for the offshore engineering foundations is convenient and cost-effective. Such foundations are often subjected to cyclic loadings, such as waves, winds, and even earthquakes. Therefore, it is necessary to evaluate the dynamic and cyclic behavior of calcareous sand.

Calcareous sands exhibit unconventional characteristics compared to those of silica sands owing to its angular nature, crushable structure, and high void ratio [1-6]. Extensive studies have investigated the dynamic properties of calcareous sands retrieved from different regions, including the North West Shelf of Australia [7-9], the west coast of Eire [10-12], Southwestern Puerto Rico [13], the north coast of Egypt [14], the Hawaiian Islands [15], the Persian Gulf [16], and the South China Sea [17-21]. Drawn from a wide range of physical, chemical, and biological geologic environments, these calcareous sands exhibit significant variability in shape, structure, gradation, and chemical composition. The biogenically induced variability of calcareous sands is therefore substantial, and can greatly influence their cyclic behavior, which is not the case for silica sands. Thus, evaluating the dynamic responses of calcareous sand requires considering different origins and physical characteristics.

This paper performed a series of undrained cyclic triaxial experiments on the calcareous sand retrieved from the South China Sea and compared the results with similar experiments on Fujian silica sand. The research results provide valuable measurements and parameters for the specific calcareous sand foundation in reef engineering.

\section{Materials and Methods}

\subsection{Materials}

The calcareous sand evaluated in this study was obtained from the South China Sea. As shown in Figure 1, it is white, uncemented, and loose sediment debris. The 
$\mathrm{CaCO}_{3}$ content in this calcareous sand is $92.67 \%$. The scanning electron micrograph of the calcareous sand with subangular to angular grains is shown in Figure 2a. The Figure $2 b$ indicates that numerous small pores are distributed on the particle surface. The particle size distributions of the tested calcareous sand and other calcareous and siliceous sands are presented in Figure 3. The coefficient of uniformity, $C_{\mathrm{u}}$; coefficient of curvature, $C_{\mathrm{c}}$; and median grain diameter, $D_{50}$, are $4.91,0.76$, and $0.53 \mathrm{~mm}$, respectively, which indicate that the particle gradation of the calcareous sand is poor. The specific gravity is 2.82 , and the maximum and minimum void ratios are 1.45 and 0.81 , respectively. Compared with other calcareous sand (Table 1), the calcareous sand tested for this paper has a larger particle size and lower porosity. Table 1 also compares the grain characteristics of common siliceous sands, including Ottawa 20-30 and Fujian sand (Figure 3). Fujian sand is a kind of pure silica sand with subrounded shapes and is commonly available in China [22,23]. The program also included specimens of Fujian silica sand tested in similar conditions for comparison purposes.

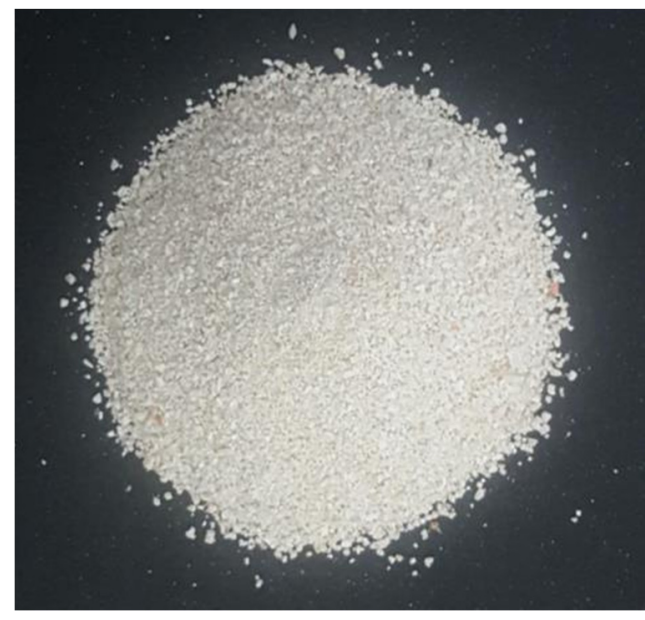

Figure 1. Photo of the tested calcareous sand.

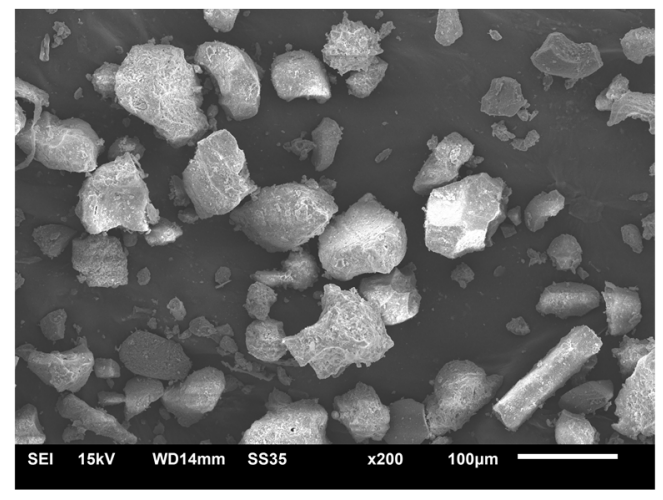

(a)

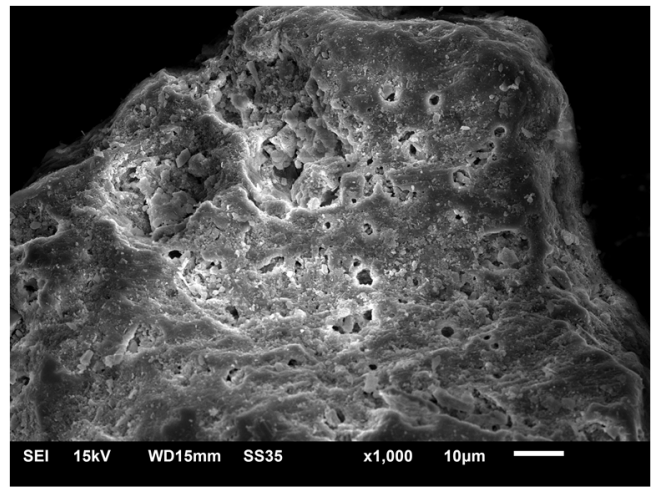

(b)

Figure 2. SEM images of the calcareous sand from the South China Sea: $(\mathbf{a}) \times 200,(\mathbf{b}) \times 1000$. 


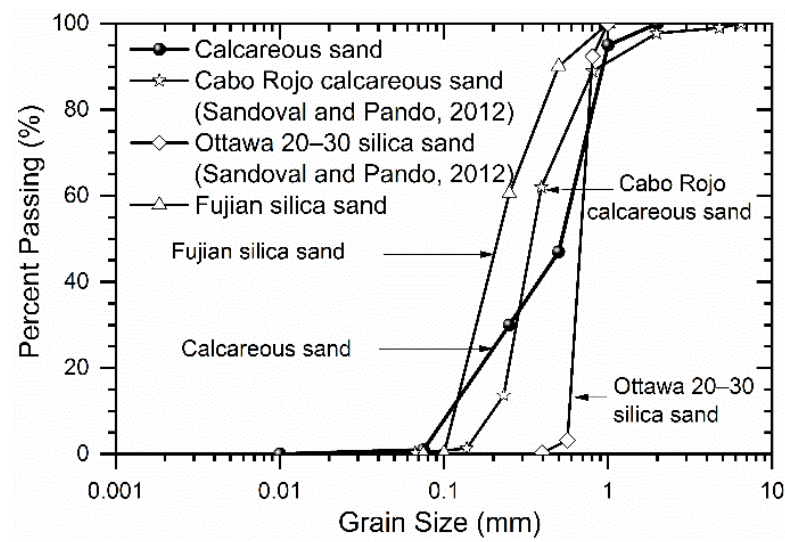

Figure 3. Particle size distribution of the calcareous sand and other calcareous and siliceous sands.

Table 1. Properties of the calcareous sand and other calcareous and siliceous sands.

\begin{tabular}{ccccccc}
\hline Category of Sand & $G_{\mathbf{s}}$ & $D_{\mathbf{5 0}}(\mathbf{m m})$ & $C_{\mathbf{u}}$ & $C_{\mathbf{c}}$ & $\boldsymbol{e}_{\mathbf{m a x}}$ & $\boldsymbol{e}_{\min }$ \\
\hline $\begin{array}{c}\text { Calcareous sand } \\
\text { (present study) }\end{array}$ & 2.82 & 0.53 & 4.91 & 0.76 & 1.45 & 0.81 \\
$\begin{array}{c}\text { Cabo Rojo calcareous sand } \\
\text { (Sandoval and Pando, 2012) }\end{array}$ & 2.84 & 0.37 & 1.75 & 0.94 & 2.07 & 1.51 \\
$\begin{array}{c}\text { Fujian silica sand } \\
\quad \text { present study) }\end{array}$ & 2.65 & 0.22 & 2.01 & 0.98 & 0.86 & 0.55 \\
$\begin{array}{c}\text { Ottawa 20-30 silica sand } \\
\text { (Sandoval and Pando, 2012) }\end{array}$ & 2.65 & 0.75 & 2.1 & 1.1 & 0.78 & 0.5 \\
\hline
\end{tabular}

\subsection{Specimen Preparation}

Reconstituted calcareous sand specimens were prepared in this experimental investigation. The water sedimentation method was conducted to prepare specimens with the relative densities of $30 \%, 45 \%$, and $60 \%$. All of the triaxial specimens were $50 \mathrm{~mm}$ in diameter and $100 \mathrm{~mm}$ in height. The back pressure saturation was conducted under an effective stress of approximately $10 \mathrm{kPa}$. A back pressure of $400 \mathrm{kPa}$ was applied to reach a $B$ value greater than 0.95 .

\subsection{Testing Program}

A series of undrained cyclic triaxial tests was conducted by the GDS dynamic triaxial equipment (DYNTTS). The loading function was sinusoidal wave, and the frequency of the cyclic loading was $1.0 \mathrm{~Hz}$. All of the cyclic triaxial tests were performed under isotropic conditions. The three main variables investigated were the relative density of specimens, $D_{\mathrm{r}}$; effective confining pressure, $\sigma_{c}^{\prime}$; and the cyclic stress ratio, CSR $=\sigma_{d} / 2 \sigma_{c}^{\prime}$, where $\sigma_{d}=$ the cyclic deviatoric stress. Table 2 presents the $D_{\mathrm{r}}, \sigma_{c}^{\prime}$, and CSR investigated for each specimen of calcareous and siliceous sand, denoted using CS and SS, respectively.

Table 2. Test conditions and results.

\begin{tabular}{ccccc}
\hline Test No. & $\boldsymbol{D}_{\mathbf{r}} \mathbf{( \% )}$ & $\sigma_{\boldsymbol{c}}{ }^{\prime} \mathbf{( k P a )}$ & CSR & $\boldsymbol{N}_{\mathbf{L}}$ \\
\hline CS1 & 30 & 100 & 0.15 & 368 \\
CS2 & 30 & 100 & 0.2 & 47 \\
CS3 & 30 & 100 & 0.25 & 13 \\
CS4 & 30 & 200 & 0.15 & 405 \\
CS5 & 30 & 200 & 0.2 & 48 \\
CS6 & 30 & 200 & 0.25 & 12 \\
CS7 & 30 & 300 & 0.15 & 397 \\
\hline
\end{tabular}


Table 2. Cont.

\begin{tabular}{ccccc}
\hline Test No. & $\boldsymbol{D}_{\mathbf{r}} \mathbf{( \% )}$ & $\sigma_{\boldsymbol{c}}{ }^{\prime} \mathbf{( k P a )}$ & CSR & $\boldsymbol{N}_{\mathbf{L}}$ \\
\hline CS8 & 30 & 300 & 0.2 & 51 \\
CS9 & 30 & 300 & 0.25 & 12 \\
CS10 & 45 & 100 & 0.2 & 67 \\
CS11 & 45 & 200 & 0.15 & 670 \\
CS12 & 45 & 200 & 0.2 & 68 \\
CS13 & 45 & 200 & 0.25 & 18 \\
CS16 & 60 & 200 & 0.15 & 4415 \\
CS17 & 60 & 200 & 0.2 & 160 \\
CS18 & 60 & 300 & 0.25 & 47 \\
CS19 & 60 & 200 & 0.2 & 150 \\
SS1 & 45 & 200 & 0.12 & 158 \\
SS2 & 45 & 200 & 0.15 & 32 \\
SS3 & 45 & & 0.18 & 11 \\
\hline
\end{tabular}

Note: CS: calcareous sand; SS: Fujian silica sand.

\section{Results}

\subsection{Undrained Cyclic Response}

Figure 4 shows the undrained behavior of the calcareous sand and Fujian silica sand at a relative density of $45 \%$ under the same CSR $=0.15$ with effective confining pressure of $\sigma_{c}^{\prime}=200 \mathrm{kPa}$. As shown in Figure 4a,b, it can be observed that the stress-strain response of the calcareous sand was not symmetrical; the strain in the extension side was larger than in the compression side. The cyclic axial strain increases at a steady rate to large values when the stress path cycles through zero- $\mathrm{p}^{\prime}$ conditions. For Fujian silica sand, the strain amplitude was very small initially, and then accelerated rapidly to amplitudes in excess of $5 \%$ as the effective mean principal stress cycled through zero, as shown in Figure 4c,d.

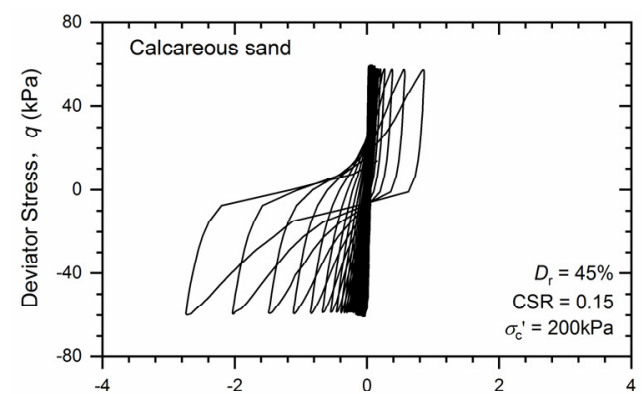

(a)
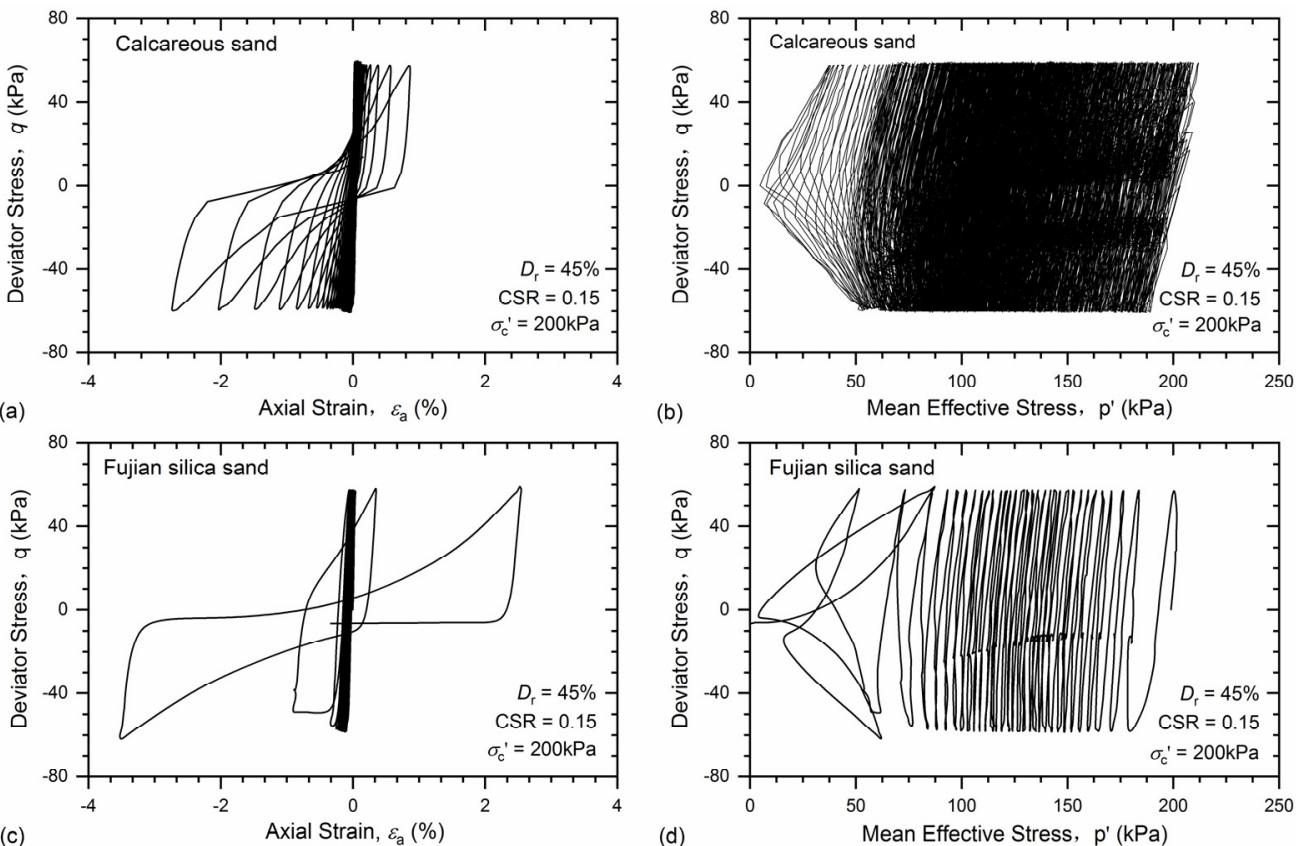

Figure 4. Typical cyclic behavior: (a) stress-strain curve for calcareous sand, (b) effective stress path for calcareous sand, (c) stress-strain curve for Fujian silica sand, (d) effective stress path for Fujian silica sand.

\subsection{Development of Excess Pore Pressure}

During cyclic loading, the liquefaction of sand occurs when excess pore pressure increases to the initial effective confining pressure. The development of excess pore pressure 
of the calcareous sand and Fujian silica sand during cyclic loading is presented in Figure 5. All of the specimens were consolidated at an effective confining pressure of $200 \mathrm{kPa}$ with a relative density of $45 \%$. As shown in Figure 5 a, the calcareous sand specimen was loaded with a CSR of 0.15 . The development of excess pore pressure showed a significant increase at the beginning and then a slower rate of accumulation until it approached the effective confining pressure, and the excess pore pressure increased significantly, thus reaching liquefaction at cycle number 670 . The behavior of the calcareous sand specimen with a CSR of 0.25 showed a gradual increase in the excess pore pressure until it reached the effective confining pressure, reaching liquefaction at cycle number 18 (Figure $5 b$ ). For Fujian silica sand with a CSR of 0.15 (Figure $5 \mathrm{c}$ ), the specimen was liquefied at 32 cycles (i.e., $N_{\mathrm{L}}=32$ ). In comparison, the calcareous sand did not liquefy until $N_{\mathrm{L}}=670$ (Figure 5a). This indicates that the calcareous sand has stronger liquefaction resistance than Fujian silica sand under the same cyclic loading conditions. Due to the angular nature of calcareous sand, particles show a more stable interlocking, which is considered to be liquefaction resistant. Figure $5 \mathrm{~d}$ shows the development of excess pore pressure in Fujian silica sand with a CSR of 0.18 , for which the cycle number that caused liquefaction is close to that of the calcareous sand with a CSR of 0.25 (Figure $5 b$ ). The excess pore pressure of Fujian silica sand increased slowly at the early stage. After cycle number 9, the excess pore pressure increased rapidly until it reached liquefaction at cycle number 11. Figure $5 b$,d illustrates differences regarding excess pore pressure development between the calcareous sand and Fujian silica sand. The calcareous sand had greater fluctuations of excess pore pressures than Fujian silica sand during cyclic loading. The large fluctuations of the calcareous sand may be due to particle rearrangement arising from the behaviors concerning contact areas between particles, including irregular shape, rough surface, and intraparticle voids. The excess pore pressure development of the calcareous sand was similar to that reported by Salem et al. [14] for calcareous sand from the north coast of Egypt.
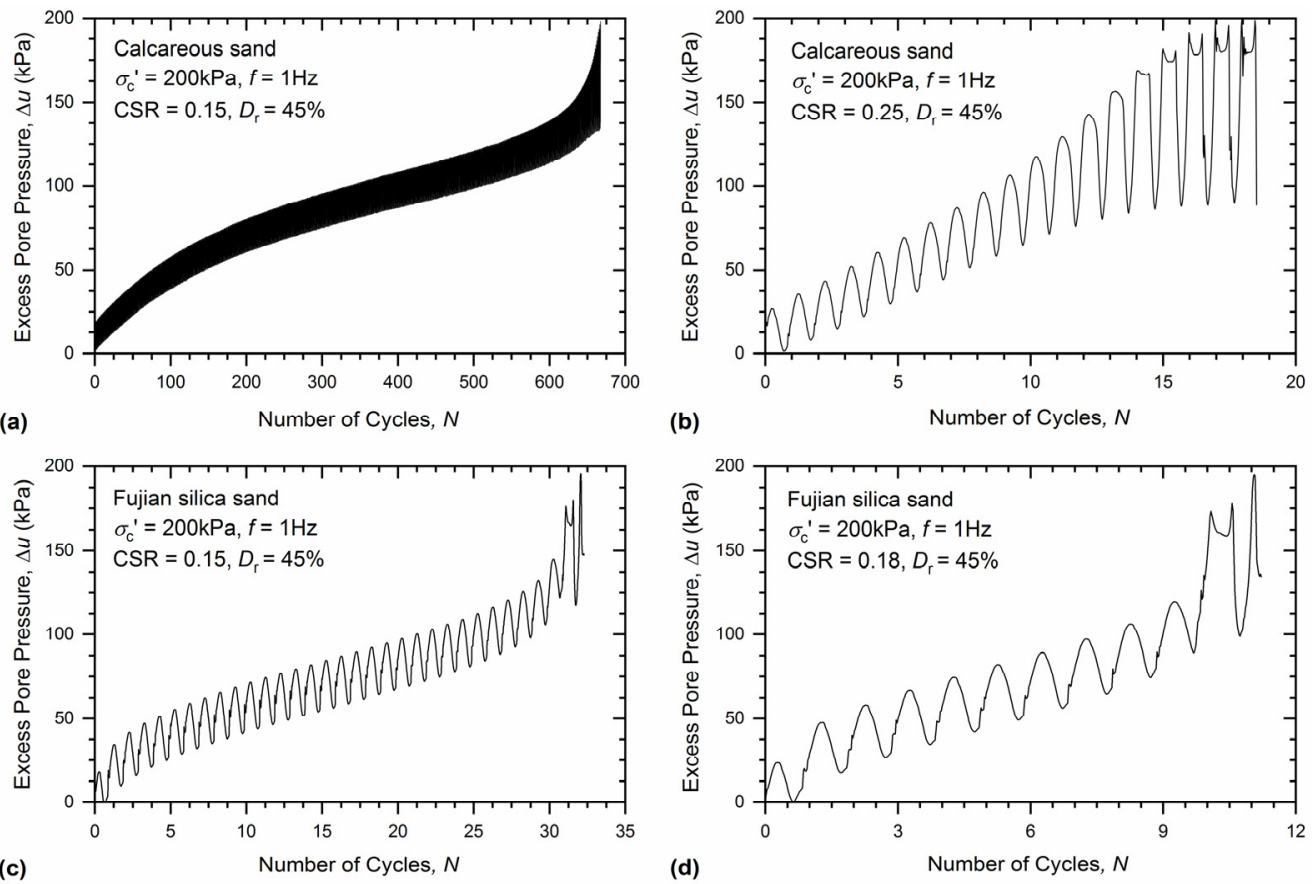

Figure 5. Development of excess pore pressure with number of cycles for the specimens under $\sigma_{c}^{\prime}=200 \mathrm{kPa}$ and $D_{\mathrm{r}}=45 \%$ : (a) calcareous sand with $\mathrm{CSR}=0.15$, (b) calcareous sand with CSR $=0.25$, (c) Fujian silica sand with CSR $=0.15$, (d) Fujian silica sand with CSR $=0.18$.

In stress-controlled cyclic triaxial tests, the residual excess pore pressures are those present when the deviator stress is zero during each cycle $[24,25]$. Figure 6 presents the residual pore pressure ratio (which is defined as the ratio of the residual excess pore pressure to the effective confining pressure, $r_{\mathrm{u}}$ ) versus the cycle ratio (which is the ratio of the 
number of loading cycles $(N)$ to the number of cycles required to cause liquefaction $\left(N_{\mathrm{L}}\right)$ ). As may be observed from Figure 6, all of the residual pore pressure development curves of the calcareous sand fell within the band of silica sand proposed by Lee and Albaisa [26]. Effective confining pressure had little influence on the pore pressure development, while the effect of CSR was profound. Due to a higher excess pore pressure development rate, the curves for the larger relative density calcareous sand were shifted upwards. The calcareous sand when cyclic loaded in the same conditions had a residual pore pressure generation curve that was similar to those for Fujian silica sand. However, the calcareous sand did not liquefy as easily as silica sand under cyclic loading.

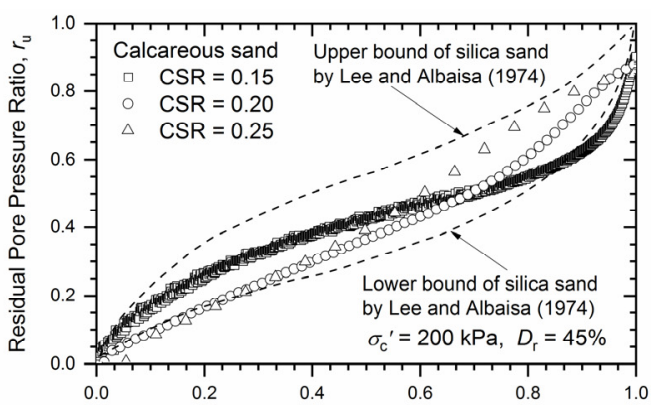

(a)

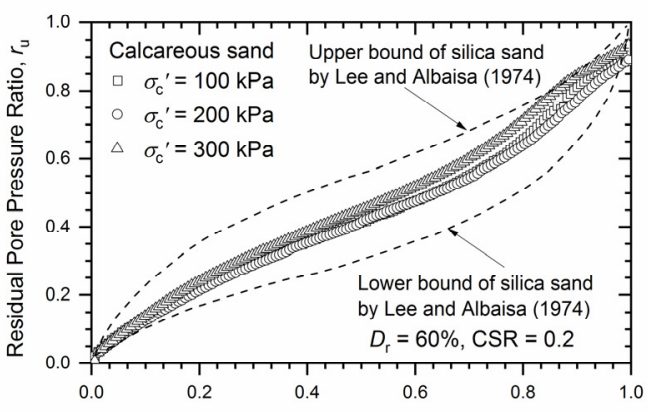

(c)

Cycle Ratio, $N / N_{\mathrm{L}}$

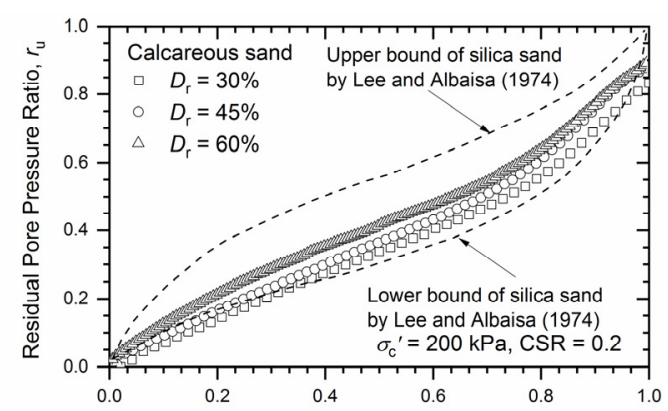

(b)

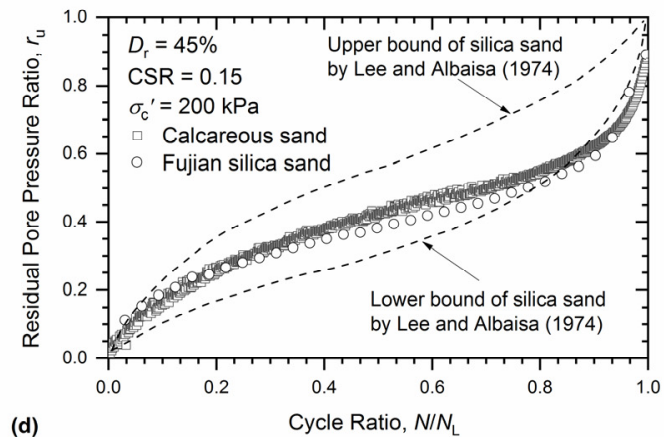

Figure 6. Comparison of residual pore pressure ratio versus cycle ratio: (a) calcareous sand with different cyclic stress ratios, (b) calcareous sand with different relative densities, (c) calcareous sand with different effective confining pressures, (d) calcareous sand and Fujian silica sand with the same loading conditions.

\subsection{Deformation Response}

Figure 7 shows the axial strain curve of the calcareous sand and Fujian silica sand. As shown in Figure 7a,b, the initial axial strains of the calcareous sand were small and then experienced a gradual accumulation until liquefaction. In contrast, the axial strain response of Fujian silica sand shown in Figure 7c,d is significantly different to that of the calcareous sand. The axial strain of Fujian silica sand was smaller than that of the calcareous sand and experienced a stabilization strain until a sudden enlargement in liquefaction. For example, the axial strain of the calcareous sand was $-1.03 \%$ at $N=15$, and increased to $-2.42 \%$ by $N_{\mathrm{L}}=18$ (Figure $7 \mathrm{~b}$ ). However, for Fujian silica sand, the amplitude axial strain was only $-0.28 \%$ at $N=9$, and achieved liquefaction at $-3.75 \%$ by $N_{\mathrm{L}}=11$ (Figure $7 \mathrm{~d}$ ). When approaching the liquefaction state, an increase in accumulated axial strain can be attributed to large soil stiffness losses as the effective stress decreases. Particle characteristic is an important reason for the difference between the calcareous sand and Fujian silica sand in the development and accumulation of axial strain. 

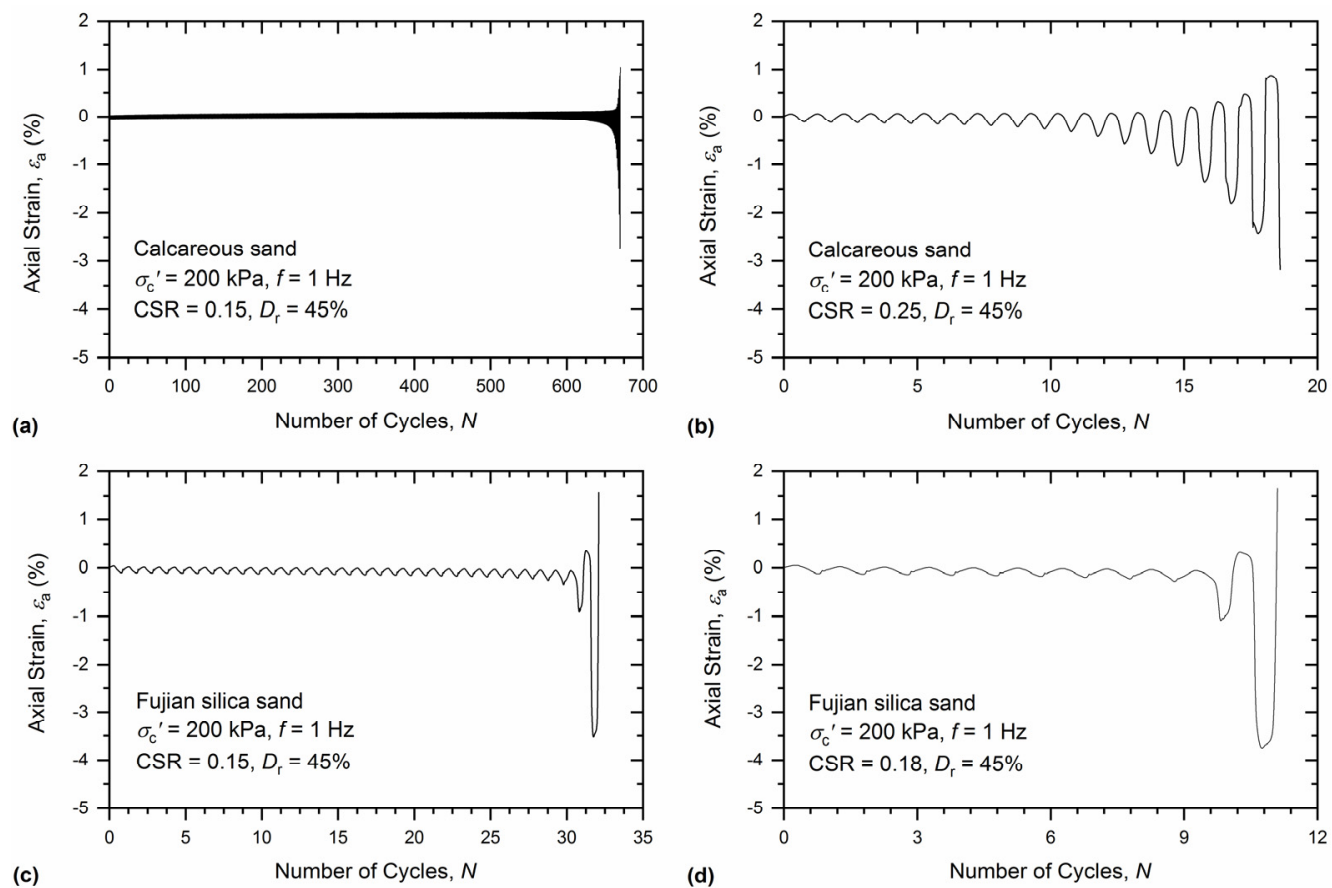

Figure 7. Axial strain versus number of cycles for the specimens under $\sigma_{c}^{\prime}=200 \mathrm{kPa}$ and $D_{\mathrm{r}}=45 \%$ : (a) calcareous sand with CSR $=0.15$, (b) calcareous sand with CSR $=0.25$, (c) Fujian silica sand with CSR $=0.15$, (d) Fujian silica sand with CSR $=0.18$.

Figure 8 shows the double amplitude axial strain at each cycle of loading versus the cycle ratio. Figure 8a shows the results of the calcareous sand with the same relative density $\left(D_{\mathrm{r}}=30 \%\right)$ and the same effective confining pressure $\left(\sigma_{c}^{\prime}=100 \mathrm{kPa}\right)$, and under different levels of CSR. As shown in Figure 8a, the strain developed on the calcareous sand was slow initially, and then the strain development rate increased. The calcareous sand specimens with CSR of $0.15,0.20$, and 0.25 started to increase strain when the cycle ratio was more than $0.9,0.8$, and 0.6 , respectively. Figure $8 \mathrm{~b}, \mathrm{c}$ shows that the strain development patterns of the calcareous sand were similar, regardless of effective confining pressure or relative density. Figure $8 \mathrm{~d}$ compares the deformation behavior of the calcareous sand and Fujian silica sand with the same $D_{\mathrm{r}}=45 \%$ and $\sigma_{c}^{\prime}=200 \mathrm{kPa}$ and a CSR of 0.15 . The double amplitude axial strains of the calcareous sand and Fujian silica sand at the beginning of cyclic loading were negligible. The difference is that the strain of calcareous sand increased gradually as soon as the cycle ratio reached 0.98 , while the strain of Fujian silica sand increased rapidly until the cycle ratio reached 0.94 .

\subsection{Shear Modulus}

During cyclic loading, the variation of stiffness is characterized by the loop stiffness $(G)$, which was determined by connecting the end points of a loop as described by Hardin and Drnevich [27]. The $G$ for each cycle is given in Figure 9. G clearly decreased during cycle loading when the cycle number increased, due to the increase in pore pressures, and the samples began to liquefy. The degradation rate and initial shear modulus of the calcareous sand are related to the cyclic loading conditions. The initial shear modulus depends on the relative density and effective confining pressure. In general, the initial shear modulus of the calcareous sand decreases with decreasing effective confining pressure and relative density (Figure 9b,c). However, CSR has little influence on the initial shear modulus (Figure 9a). The degradation rate of the shear modulus increases with the increasing CSR and the decreasing relative density (Figure $9 a, b$ ). The effect of effective confining pressure is not good (Figure 9c). As shown in Figure 9d, the initial shear modulus of silica sand is lower than that of the calcareous sand, and the shear modulus of silica sand drastically decreased during cyclic loading. 

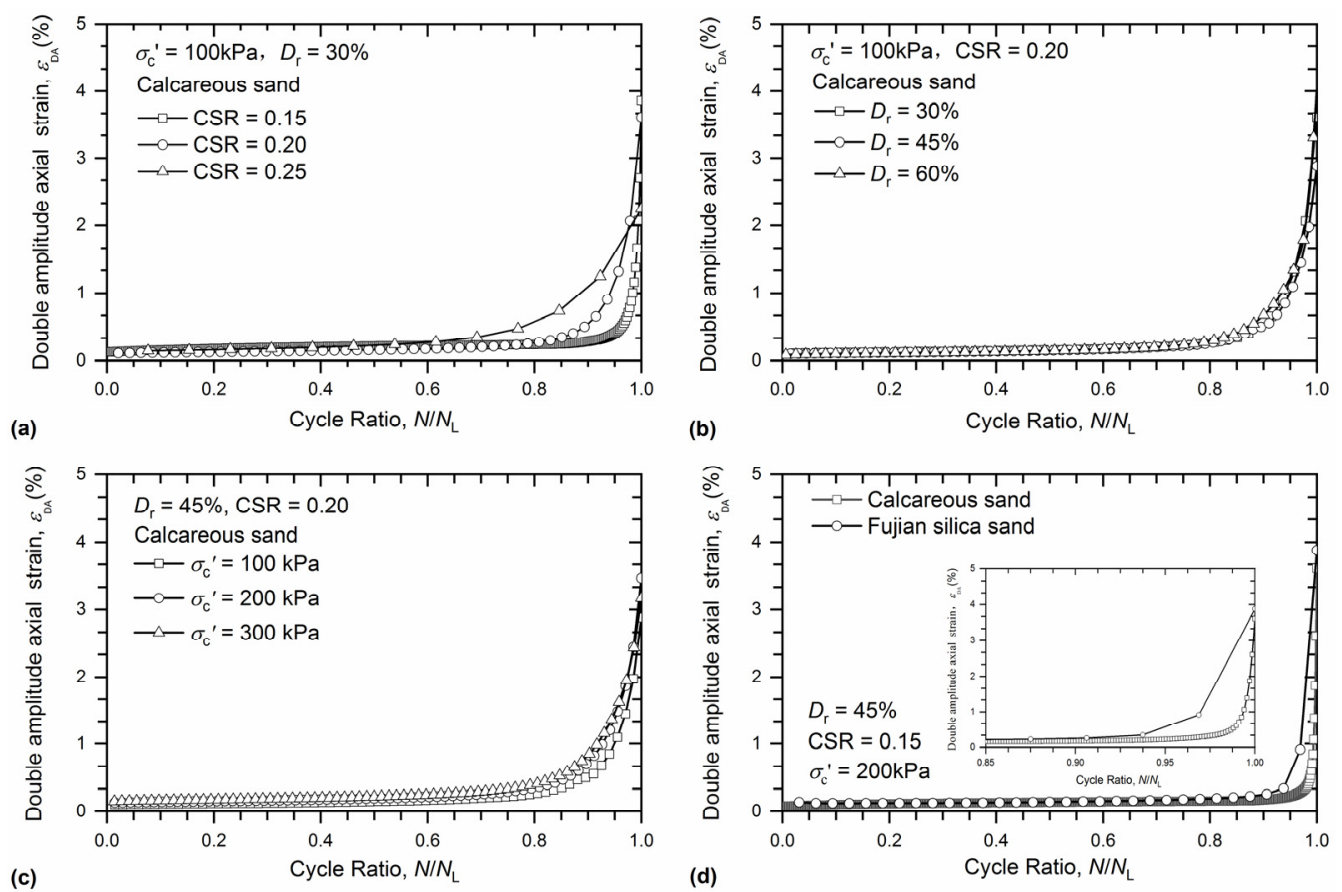

Figure 8. Comparison of double amplitude axial strain versus cycle ratio: (a) calcareous sand with different cyclic stress ratios, (b) calcareous sand with different relative densities, (c) calcareous sand with different effective confining pressures, (d) calcareous sand and Fujian silica sand with the same loading conditions.
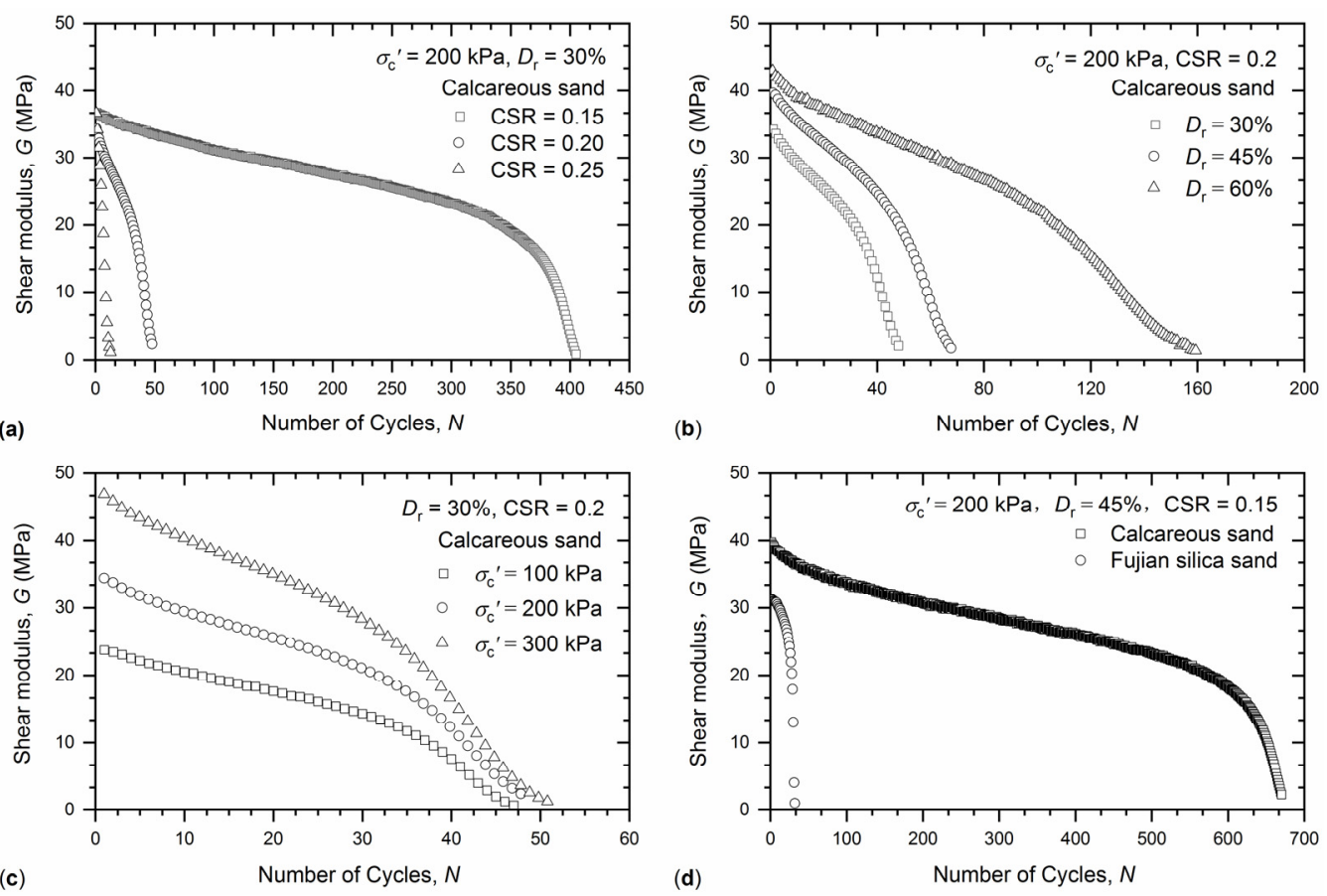

Figure 9. Comparison of shear modulus versus number of cycles: (a) calcareous sand with different cyclic stress ratios, (b) calcareous sand with different relative densities, (c) calcareous sand with different effective confining pressures, (d) calcareous sand and Fujian silica sand with the same loading conditions.

\subsection{Cyclic Strength}

The cyclic strength is defined as the relationship between the cyclic stress ratio (CSR) and the number of cycles required to liquefaction $\left(N_{L}\right)$. The cyclic strength curves of 
calcareous sand under different relative densities and effective confining pressures are presented in Figure 10. The results show that the number of cycles to liquefaction decreased as CSR increased for calcareous sand. The higher the relative density, the larger the number of cycles to liquefaction. Similar trends have been found in other calcareous sands $[11,13,14]$. The results also showed that the effective confining pressure has little effect on the calcareous sand for relative densities ranging from $30 \%$ to $60 \%$, which differs from the results of previous studies.

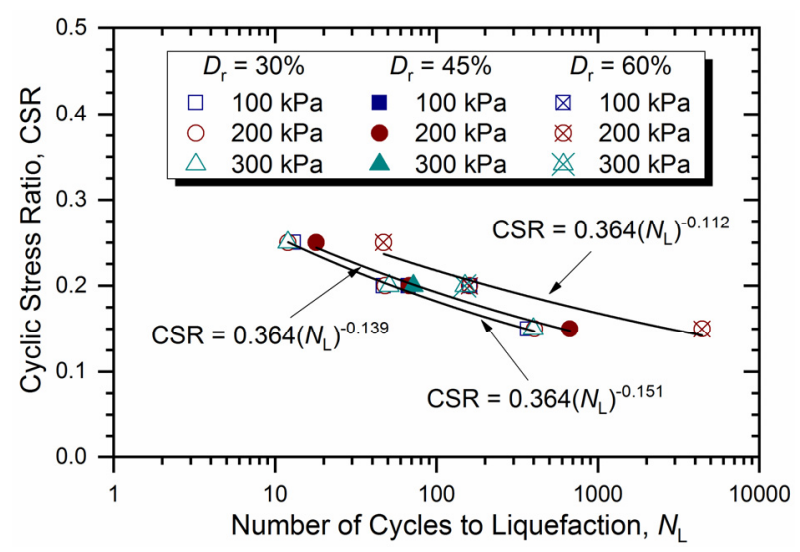

Figure 10. Cyclic strength curves for the calcareous sand.

Figure 11 shows data for the calcareous sand at relative densities of $30 \%, 45 \%$, and $60 \%$ over a range of effective confining pressures (100 to $300 \mathrm{kPa}$ ), and for comparison purposes, includes the data for Cabo Rojo calcareous sand at relative densities of $45 \%$, $65 \%$, and $80 \%$ for effective confining pressures of 100 and $200 \mathrm{kPa}$ [13]. It was shown that all of the cyclic strength of calcareous sand increased with increasing relative densities. The range of the cyclic strength of Cabo Rojo calcareous sand was larger than that of the calcareous sand. The cyclic strength of calcareous sand was greater than that of Cabo Rojo calcareous sand at relative densities of $45 \%$, while the cyclic strength of calcareous sand was slightly less than that of Cabo Rojo calcareous sand at relative densities of $60 \%$. There appeared to be a dependence on confining pressure for Cabo Rojo calcareous sand, with an increase in cyclic strength as the confining pressure decreased, which is similar to the behavior of Dogs Bay calcareous sand [11] and Dabaa calcareous sand [14]. However, there was no confining-pressure effect on the calcareous sand in this range of relative densities. The variations in the locations, compositions, soil structure, intraparticle voids, and particle shape may explain the variation in cyclic strength of calcareous sands from different regions.

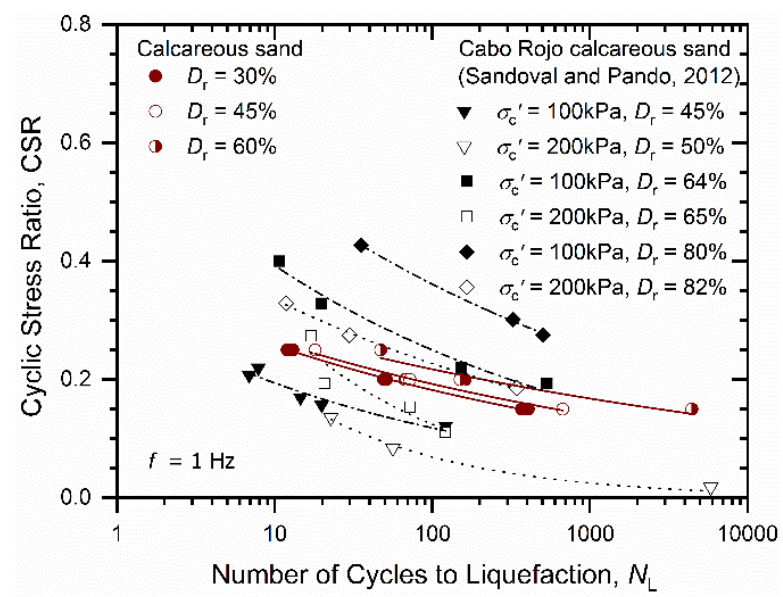

Figure 11. Comparison between the calcareous sand and Cabo Rojo calcareous sand. 
Figure 12 shows data for the calcareous sand at relative densities of $30 \%, 45 \%$, and $60 \%$ over a range of confining pressures (100 to $300 \mathrm{kPa}$ ), and for comparison purposes, includes Fujian silica sand at relative densities of 45\% and Ottawa 20-30 silica sand at relative densities of $25 \%$ and $68 \%$ [13]. The calcareous sand showed higher cyclic strength than both Fujian silica sand and Ottawa 20-30 silica sand in this range of relative densities. The higher cyclic strength is due to the angular shape of calcareous sand particles, which has more stable interlocking soil fabric that is resistant to liquefaction.

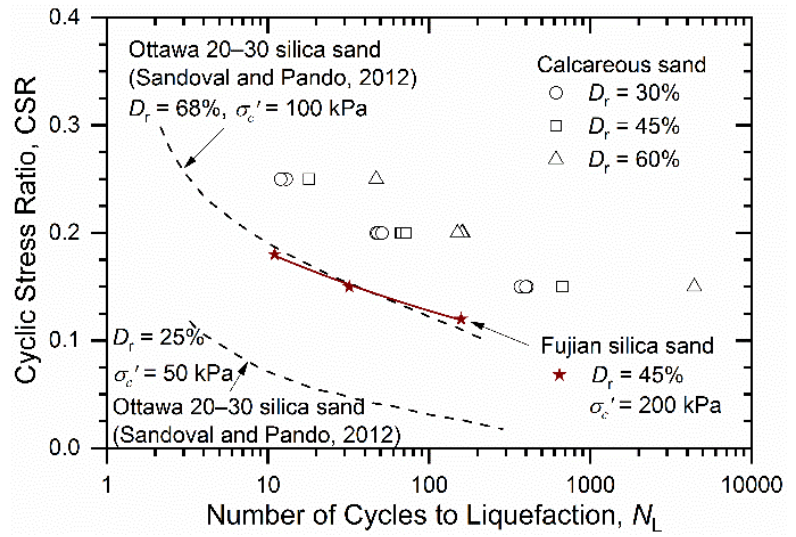

Figure 12. Comparison between the calcareous sand and Fujian and Ottawa 20-30 silica sand.

\section{Conclusions}

This paper presents the cyclic behavior of the calcareous sand in the South China Sea and highlights the differences between the calcareous sand and Fujian silica sand. The following conclusions can be drawn from the results analyzed in this paper:

(1) During the cyclic triaxial test, both the excess pore pressure and axial strain of the calcareous sand gradually increased as it reached liquefaction, whereas for Fujian silica sand, a sudden increase in excess pore pressure and axial strain was observed when approaching liquefaction state.

(2) The calcareous sand had greater liquefaction resistance than Fujian silica sand tested under same cyclic loading conditions. This may be attributed to the angular nature of calcareous sand particles providing more stable interlocking soil fabric that is resistant to liquefaction.

(3) The CSR had a significant effect on the cyclic behavior of calcareous sand, including excess pore pressure development, deformation response, the degradation rate of the shear modulus, and cyclic strength. However, there was little confining-pressure effect on the cyclic behavior of calcareous sand, which is different from other calcareous sands. This may be attributed to the variations in regions and grain composition, which warrants further study.

Author Contributions: Conceptualization, L.L. and H.G.; methodology, L.L. and H.G.; validation, L.L. and X.Y.; investigation, L.L. and X.Y.; resources, Z.W. and H.G.; data curation, X.Y. and Z.J.; writing-original draft, L.L. and X.Y.; writing—review and editing, Z.J., Z.W. and Z.S.; visualization, L.L. and X.Y.; supervision, Z.W. and H.G. All authors have read and agreed to the published version of the manuscript.

Funding: This work was supported by the National Natural Science Foundation of China (grant no. 52008207, 51908284 and 51678300), Natural Science Research Project of Colleges and Universities in Jiangsu Province of China (grant no. 18KJA560002 and 19KJB560015), and the Middle-Aged and Young Science Leaders of Qinglan Project of Universities in Jiangsu Province of China.

Institutional Review Board Statement: Not applicable.

Informed Consent Statement: Not applicable.

Conflicts of Interest: The author declare no conflict of interest. 


\section{References}

1. Coop, M.R. The mechanics of uncemented carbonate sands. Géotechnique 1990, 40, 607-626. [CrossRef]

2. Miao, G.; Airey, D. Breakage and ultimate states for a carbonate sand. Géotechnique 2013, 63, 1221-1229. [CrossRef]

3. Liu, L.; Liu, H.L.; Xiao, Y.; Chu, J.; Xiao, P.; Wang, Y. Biocementation of calcareous sand using soluble calcium derived from calcareous sand. Bull. Eng. Geol. Environ. 2018, 77, 1781-1791. [CrossRef]

4. Liu, L.; Liu, H.L.; Stuedlein, A.W.; Evans, T.M.; Xiao, Y. Strength, Stiffness, and Microstructure Characteristics of Biocemented Calcareous Sand. Can. Geotech. J. 2019, 56, 1502-1513. [CrossRef]

5. Wu, Y.; Li, N.; Wang, X.; Cui, J.; Chen, Y.; Wu, Y.; Yamamoto, H. Experimental investigation on mechanical behavior and particle crushing of calcareous sand retrieved from South China Sea. Eng. Geol. 2020, 280, 105932. [CrossRef]

6. Wang, X.; Wu, Y.; Cui, J.; Zhu, C.Q.; Wang, X.Z. Shape Characteristics of Coral Sand from the South China Sea. J. Mar. Sci. Eng. 2020, 8, 803. [CrossRef]

7. Airey, D.W.; Fahey, M.D. Cyclic response of calcareous soil from the North-West Shelf of Australia. Géotechnique 1991, 41, 101-121. [CrossRef]

8. Mao, X.; Fahey, M. Behaviour of calcareous soils in undrained cyclic simple shear. Géotechnique 2003, 53, 715-727. [CrossRef]

9. Sharma, S.S.; Ismail, M.A. Monotonic and cyclic behavior of two calcareous soils of different origins. J. Geotech. Geoenviron. Eng. 2006, 132, 1581-1591. [CrossRef]

10. Hyodo, M.; Aramaki, N.; Itoh, M.; Hyde, A.F.L. Cyclic strength and deformation of crushable carbonate sand. Soil Dyn. Earthq. Eng. 1996, 15, 331-336. [CrossRef]

11. Hyodo, M.; Hyde, A.F.L.; Aramaki, N. Liquefaction of crushable soils. Géotechnique 1998, 48, 527-543. [CrossRef]

12. Qadimi, A.; Coop, M.R. The undrained cyclic behaviour of a carbonate sand. Géotechnique 2007, 57, 739-750. [CrossRef]

13. Sandoval, E.A.; Pando, M.A. Experimental assessment of the liquefaction resistance of calcareous biogenous sands. Earth Sci. Res. J. 2012, 16, 55-63. [CrossRef]

14. Salem, M.; Elmamlouk, H.; Agaiby, S. Static and cyclic behavior of North Coast calcareous sand in Egypt. Soil Dyn. Earthq. Eng. 2013, 55, 83-91. [CrossRef]

15. Brandes, H.G. Simple shear behavior of calcareous and quartz sands. Geotech. Geol. Eng. 2011, 29, 113-126. [CrossRef]

16. Shahnazari, H.; Rezvani, R.; Tutunchian, M.A. Post-cyclic volumetric strain of calcareous sand using hollow cylindrical torsional shear tests. Soil Dyn. Earthq. Eng. 2019, 124, 162-171. [CrossRef]

17. Xiao, P.; Liu, H.L.; Xiao, Y.; Stuedlein, A.W.; Evans, T.M. Liquefaction resistance of bio-cemented calcareous sand. Soil. Dyn. Earthq. Eng. 2018, 107, 9-19. [CrossRef]

18. Xiao, P.; Liu, H.L.; Stuedlein, A.W.; Evans, T.M.; Xiao, Y. Effect of relative density and biocementation on cyclic response of calcareous sand. Can. Geotech. J. 2019, 56, 1849-1862. [CrossRef]

19. He, S.H.; Zhang, Q.F.; Ding, Z.; Xia, T.D.; Gan, X.L. Experimental and Estimation Studies of Resilient Modulus of Marine Coral Sand under Cyclic Loading. J. Mar. Sci. Eng. 2020, 8, 287. [CrossRef]

20. Wu, Q.; Ding, X.M.; Zhang, Y.L.; Chen, Z.X. Comparative Study on Seismic Response of Pile Group Foundation in Coral Sand and Fujian Sand. J. Mar. Sci. Eng. 2020, 8, 189. [CrossRef]

21. Zhou, X.Z.; Chen, Y.M.; Liu, H.L.; Zhang, X.Z. Experimental study on the cyclic behavior of loose calcareous sand under linear stress paths. Mar. Georesour. Geotec. 2020, 38, 277-290. [CrossRef]

22. Yang, J.; Sze, H.Y. Cyclic strength of sand under sustained shear stress. J. Geotech. Geoenviron. Eng. 2011, 137, 1275-1285. [CrossRef]

23. Chen, G.X.; Wu, Q.; Zhao, K.; Shen, Z.F.; Yang, J. A Binary Packing Material-Based Procedure for Evaluating Soil Liquefaction Triggering during Earthquakes. J. Geotech. Geoenviron. Eng. 2020, 146, 4020040. [CrossRef]

24. Seed, H.B.; Lee, K.L. Liquefaction of saturated sands during cyclic loading. J. Soil Mech. Found. Div. 1966, 92, 105-134. [CrossRef]

25. Polito, C.P.; Green, R.A.; Lee, J. Pore pressure generation models for sands and silty soils subjected to cyclic loading. J. Geotech. Geoenviron. Eng. 2008, 134, 1490-1500. [CrossRef]

26. Lee, K.L.; Albaisa, A. Earthquake induced settlements in saturated sands. J. Geotech. Engng Div. 1974, 100, 387-406. [CrossRef]

27. Hardin, B.O.; Drnevich, V.P. Shear modulus and damping in soils: Design equations and curves. J. Soil Mech. Found. Div. 1972, 98, 667-692. [CrossRef] 